\title{
Commentary Achieving the aims of education: curricular decisions in critical care
} Timothy G Buchman

\author{
Departments of Surgery, Anesthesiology and Medicine, Washington University in Saint Louis, Mail Stop 8109, 660 South Euclid Avenue, Saint Louis, \\ MI 63110, USA
}

Corresponding author: Timothy G Buchman, buchman@wustl.edu

Published: 5 November 2008

This article is online at http://ccforum.com/content/12/6/188

(c) 2008 BioMed Central Ltd

Critical Care 2008, 12:188 (doi:10.1186/cc7094)

See related research by Peets et al., http://ccforum.com/content/12/5/R127

\begin{abstract}
Curricula for residents on rotations through intensive care units are necessarily abbreviated. The selection (and omission) of topics can be informed by assessment of perceived needs. A curriculum cannot, however, be formed exclusively from the top-scoring needs. Topics that are encountered exclusively in the critical care unit (such as brain death) must be included.
\end{abstract}

The mind is never passive; it is a perpetual activity, delicate, receptive, responsive to stimulus. You cannot postpone its life until you have sharpened it. Whatever interest attaches to your subject-matter must be evoked here and now; whatever powers you are strengthening in the pupil, must be exercised here and now; whatever possibilities of mental life your teaching should impart, must be exhibited here and now. That is the golden rule of education, and a very difficult rule to follow.

(Alfred North Whitehead, Presidential Address to the Mathematical Association, January 1916)

Peets and colleagues report on a strategy for selecting content for inclusion in a critical care curriculum for residents [1]. The authors constructed a three-domain classification of common clinical problems and asked resident trainees and attendings to score each problem according to the threat to life, to frequency and to reversibility. The scales were organized to give greatest weight to greater life-threat, higher frequency and ease of reversibility. The authors report strong concurrence between the product of domain scores of resident trainees and of their supervising attending physicians. In their conclusion, the authors assert that their process is widely applicable and 'can facilitate creation of a reliable and valid curriculum' [1].
It is unsurprising that residents and their teaching staff should have similar assessments of the three objective features listed. For example, brain death - which appears at the bottom of the priority list - is irreversible by definition. If any resident or attending scored brain death as anything other than not reversible, it would be at once surprising and problematic. Similarly, the frequency of the condition of brain death in the intensive care unit (ICU) studied and the degree to which brain death threatens life are not matters for debate.

What is of greater concern, however, is that the methodology advanced by the authors results in brain death being placed at the very bottom of the needs assessment. The authors state in their key messages that their tool 'will provide content validity for any curriculum' [1]. Herein lies the greatest problem with the methodology: it overvalues those curricular elements that focus on reversible conditions. The unfortunate fact is that many patients are admitted to the ICU with conditions that either will not respond to critical care or are terminal, or both. Curricula that fail to forthrightly confront this reality perpetuate costly and quixotic efforts to cure where care would be more appropriately directed towards comfort and dignity. Brain death is one of several victims of the authors' methodology. The same scoring logic relegates endof-life decision-making, arguably one of the most important activities in any ICU, to a level of importance below that of obstetrical complications.

The critical question left unaddressed in the methodology proposed for selecting curricular elements is whether the topics most highly ranked can be uniquely and best learned in the ICU. For example, topics such as shock, seizure and drug overdose are highly ranked, but are also frequently encountered in the emergency department. Obstetrical complications are surely encountered in obstetrics rotations. In contrast, the management of acute and fulminant hepatic

$\mathrm{ICU}=$ intensive care unit. 
failure, and the strategies that reverse those conditions or else indicate the need for transplantation, can only be learned in the ICU. Yet acute and fulminant hepatic failure ranks just above brain death in the needs assessment listing.

In summary, the authors should be complimented for conducting a needs assessment and also for reporting strong concurrence between trainees and supervisors. The report should serve as a basis for ensuring that acute and critical care topics are covered within a comprehensive curriculum spanning the entire training period. The fact that a condition might not be reversible should not diminish its importance in the ICU curriculum. On the contrary, one might reasonably argue that brain death, fulminant organ failure and end-of-life decision-making ought to be pushed near the top of the priority list. If these topics are not explored during the ICU rotation of the trainees, then where?

\section{Competing interests}

The author discloses that he is the USA reporter for CoBaTRICE.

\section{Reference}

1. Peets $A D$, McLaughlin K, Lockyer J, Donnon $T$ : So much to teach, so little time: a prospective cohort study evaluating a tool to select content for a critical care curriculum. Crit Care 2008, 12:R127. 